\title{
Attentiveness of pediatricians to primary immunodeficiency disorders
}

\author{
Suleiman Al-Hammadi ${ }^{*}$, Eiman Al-Reyami ${ }^{2}$, Sareea Al-Remeithi ${ }^{3}$, Khawla Al-Zaabii ${ }^{4}$ Rola Al-Zir ${ }^{5}$, Heba Al-Sagban ${ }^{6}$, \\ Taoufik Zoubaidi ${ }^{7}$ and Abdul-Kader Souid ${ }^{1}$
}

\begin{abstract}
Background: Primary immunodeficiency (PID) is a cluster of serious disorders that requires special alertness on the part of the medical staff for prompt diagnosis and management of the patient. This study explored PID knowledge and experience among pediatricians of wide educational backgrounds, practicing in the United Arab Emirates (UAE).

Method: A self-administered questionnaire was used to determine the competency of pediatricians in their knowledge of PID disorders. This study questionnaire included questions on PID signs and symptoms, syndromes associated with immunodeficiency, screening tests, interpreting laboratory tests and case management. The participants were 263 pediatricians of diverse education working in the 27 governmental hospitals in all regions of UAE.

Results: The overall performance of the pediatricians did not differ based on their age, gender, origin of certification, rank, or years of experience. Of the 50 questions, $20 \%$ of pediatricians answered correctly $<60 \%$ of the questions, $76 \%$ answered correctly 60 to $79 \%$ of the questions, and $4 \%$ answered correctly $\geq 80 \%$ of the questions. Seventeen of the 19 PID signs and symptoms were identified by 55 to 97\%. Four of 5 syndromes associated with immunodeficiency were identified by 50 to $90 \%$. Appropriate screening tests were chosen by 64 to $96 \%$. Attention to the laboratory reference range values as function of patient age was notably limited.
\end{abstract}

Conclusions: There was a noteworthy deficiency in PID work-up. Therefore, implementing effective educational strategies is needed to improve the competency of pediatricians to diagnose and manage PID disorders.

Keywords: Survey, Primary immunodeficiency, Knowledge, Diagnosis, Management

\section{Background}

Primary immunodeficiency (PID) is a cluster of disorders that share a common theme of excessive susceptibility to infection and other associated clinical problems [1,2]. These serious episodes of infection markedly impair the patients' ability to lead a normal life [3,4]. While individual diseases are rare, PID as an entity is not uncommon [1]. To date, there are more than 160 genetically distinct PID diseases [5], affecting more than 10 million children and adults worldwide [6]. As appropriately stated, PID is common enough that a primary care physician is likely to encounter several patients in their practice [7]. Wood et al. indicated that diagnostic delays remain common,

\footnotetext{
* Correspondence: suleiman.alhammadi@uaeu.ac.ae

${ }^{1}$ Department of Pediatrics, Faculty of Medicine and Health Sciences, UAE University, P.O. Box 17666, Al-Ain, United Arab Emirates

Full list of author information is available at the end of the article
}

mostly due to limited awareness of the heterogeneity and presenting features of PID [8].

Familiarity of pediatricians with PID is essential for the early diagnosis and case management. Inadequate clinical and laboratory assessments account for most of the deferred diagnoses that may result in organ impairments $[1,2]$. A recent study suggested the awareness initiatives and educational programs should especially target pediatricians, hospitalists and families with members who have PID [9].

Historically, medical surveys addressing PID disorders have served various clinical needs, including identifying educational gaps. The United Arab Emirates (UAE) are especially distinguished by the diversity of medical education backgrounds of their pediatricians, which makes educational questionnaires especially meaningful and consequential. Moreover, parental consanguinities are typical in UAE, accounting for the possibility of a high

\section{() BioMed Central}

(c) 2012 Al-Hammadi et al.; licensee BioMed Central Ltd. This is an Open Access article distributed under the terms of the Creative Commons Attribution License (http://creativecommons.org/licenses/by/2.0), which permits unrestricted use, distribution, and reproduction in any medium, provided the original work is properly cited. 
occurrence of PID. However, since there is no national registry of $\mathrm{PID}$ in UAE, the prevalence of PID is unknown. For similar cultures, parental consanguinity among PID patients was found to be $\sim 77 \%$ in Kuwait [10], $\sim 66 \%$ in Iran [11] and $~ 63 \%$ in Egypt [12].

The primary objective of this study was to explore PID knowledge and experience among pediatricians of diverse educational backgrounds and practicing environments. The other objective was to identify educational gaps that needed to be overcome to improve the care of children with PID.

\section{Methods}

A self-reported questionnaire was used to explore PID experience among pediatricians in UAE. The feasibility was assessed initially in the first 10 participating pediatricians. The questions were clear and fully answered.

Sixty-three items were included in the survey. Six questions looked at personal information, 24 at PID signs and symptoms, 9 at associated syndromes, 11 at screening tests, 6 at laboratory interpretations and 7 at management. The implemented questions were a modification of those developed by Al-Herz et al. [13].

There were 27 government-based hospitals in UAE; these centers provided community and tertiary services across the country. All these medical facilities were included in the survey. The total number of pediatricians working in these hospitals was 422; 263 (62.3\%) pediatricians of them were recruited and participated in the study.

Data were analyzed using SPSS statistical package (version 19). Poisson regression models were used to test for significant differences in the score (correct answers) in PID knowledge and investigation. The variables included pediatricians' age, gender, certification, rank and years of experience.

The Poisson regression models fitted the data well; the $p$-values of Likelihood Ratio tests for goodness-of-fit were all $>0.90$. Comparison of the median relative scores (percentage of correct answers) in PID knowledge and investigation were done using the Wilcoxon signed rank test. The same test was also used to obtain confidence intervals for the median relative scores in various components of the questionnaire (signs and symptoms, syndromes associated with immunodeficiency, screening tests and laboratory interpretation). The Wilcoxon nonparametric test was used because neither the relative scores nor their arcsine transformations (angular transformation) were normally distributed (Shapiro-Wilk test $p<0.001)$. The chi-square test for goodness-of-fit was used to compare the frequency of responses in each of the following variables: IVIG dosing, dosing intervals, and prophylactic antibiotic choices. A $p \leq 0.05$ was considered significant.
The study was approved by the Ethics Committee of the Faculty of Medicine and Health Sciences at UAE University (No. 09/51).

\section{Results}

Two hundred sixty three pediatricians (59\% male) participated in the study. Their age (mean \pm SD) was $42.1 \pm 9.6$ years.

Twenty-two percent had FRCP (or MRCP), 13\% Pediatric Arab Board, 12\% Diploma of Child Health, 11\% Pediatric American or Canadian Board, and 41\% other certifications (e.g., FACHARTZ and Master Degrees). Fifty percent were Specialists, 26\% were house officers (or pediatric residents) and $24 \%$ were consultants. Forty-one percent practiced pediatrics $<10$ years, $40 \% 10$ to 20 years, and $19 \%>20$ years $($ mean $\pm \mathrm{SD}=13.4 \pm 9.0$ years; range $=$ 1 to 40 years).

Table 1 shows the frequency of recognizing common PID signs and symptoms. Nineteen items pointed to PID signs and symptoms and 5 items (labeled with asterisks) were not. These manifestations were chosen to cover the

Table 1 Which of the following signs and symptoms make you suspect PID?

\begin{tabular}{|c|c|}
\hline & Percent answered "yes" \\
\hline Persistent oral thrush & 97 \\
\hline Infections with uncommon organisms & 96 \\
\hline Failure of infant to thrive & 90 \\
\hline Sepsis with atypical mycobacteria & 83 \\
\hline Severe dermatitis & 81 \\
\hline Two invasive deep seated infections & 80 \\
\hline Delayed wound healing & 79 \\
\hline Death of a sibling in infancy & 77 \\
\hline Absent tonsils & 75 \\
\hline Autoimmune cytopenia & 65 \\
\hline Partial albinism & 65 \\
\hline Lymphoma & 64 \\
\hline Otitis media ( 5 bouts per year) & 62 \\
\hline Interrupted aortic arch & 62 \\
\hline Pneumonia ( 2 bouts per year) & 59 \\
\hline Severe warts & 57 \\
\hline Severe periodontitis & 55 \\
\hline Polyendocrinopathy & 48 \\
\hline Dextrocardia * & 45 \\
\hline Transfusion reaction & 44 \\
\hline Malar rash * & 28 \\
\hline Inguinal lymphadenopathy * & 22 \\
\hline Polydactaly * & 20 \\
\hline Ventricular septal defect * & 9 \\
\hline
\end{tabular}

*Does not increase likelihood of PID.

(The order of the items is presented according to the percentage picked by respondents, not how it appeared in the questionnaire). 
four main components of the immune system, i.e., antibody deficiency, T-cells defect, neutrophil defect and complement deficiency. Five of the "ten warning signs" of PID [6] were included in the list (36\% of participants answered the 5 questions correctly, 31\% answered 4 questions correctly and $33 \%$ answered 1-3 questions correctly). Seventeen of the 19 PID signs and symptoms were frequently (55 to $97 \%$ ) selected. Polyendocrinopathy and transfusion reaction were the least selected (48\% and $44 \%$, respectively). The five distractants were much less frequently selected.

Table 2 shows the frequency of recognizing syndromes or conditions that may associate with PID [14]. Similarly, 4 of 5 syndromes associated with immunodeficiency were frequently (50 to $90 \%$ ) selected. The four distractants (labeled with asterisks) were much less $(\leq 20 \%)$ selected. The results in Tables 1, 2 show PID knowledge is not limited in this cluster of pediatricians, despite their broad educational diversity.

Table 3 shows the frequency of selecting appropriate PID screening tests. Four items (complete blood counts with differential, quantitative serum immunoglobulins, lymphocyte subsets and chest $\mathrm{x}$-ray) are stressed to be the initial screening before the next level of evaluation [2]. The remaining items (labeled with asterisks) were either next level of investigation (antibody titers to previous vaccines, lymphocyte stimulation, neutrophil oxidative burst, IgG subclasses and total complements), not commonly used (serum isohemagglutinins) or inappropriate (chest CT scan) [15]. The four appropriate screening tests were highly selected (64 to $96 \%$ ). Unnecessary tests were frequently requested for screening, and selecting appropriate initial work-up of PID was imprecise. For example, IgG subclasses were selected as a screening test in $77 \%$ and neutrophil oxidative burst in 66\%.

Table 4 included six laboratory findings; three of them were age-dependent. Absent delayed hypersensitivity

Table 2 Which of the following syndromes or conditions may associate with PID?

\begin{tabular}{ll}
\hline & Percent answered "yes" \\
\hline Ataxia telangiectasia & 90 \\
\hline Bloom syndrome & 67 \\
\hline Cartilage hair hypoplasia & 58 \\
\hline Ectodermal dysplasia & 50 \\
\hline Short-limb dwarfism & 33 \\
\hline Ehler Danlos syndrome * & 20 \\
\hline Hurler syndrome * & 18 \\
\hline Turner syndrome * & 13 \\
\hline Sturge Weber syndrome * & 9 \\
\hline * Not associated with PID. \\
(The order of the items is presented according to the percentage picked by \\
respondents, not how it appeared in the questionnaire).
\end{tabular}

Table 3 Which of the following tests would you request for PID initial screening?

\begin{tabular}{ll}
\hline CBC with differential & Percent answered "yes" \\
\hline Serum immunoglobulin levels & 96 \\
\hline lgG subclasses * & 96 \\
\hline Chest x-ray & 77 \\
\hline Neutrophil oxidative burst assay* & 76 \\
\hline Antibody titers to previous vaccines * & 66 \\
\hline Lymphocyte subsets & 64 \\
\hline Total complements* & 64 \\
\hline Lymphocyte stimulation tests * & 56 \\
\hline Serum isohemagglutinins * & 44 \\
\hline Chest CT scan * & 40 \\
\hline
\end{tabular}

* Not recommended as a first-line screening.

(The order of the items is presented according to the percentage picked by respondents, not how it appeared in the questionnaire).

skin reaction to Candida is only abnormal after 12 months of age [16]; this item was incorrectly selected by $74 \%$. The absolute lymphocyte count at 2 to 5 months of age should be $>3,700 / \mu \mathrm{L}$; thereafter, it decreases gradually to $>1,700 / \mu \mathrm{L}$ by 2 years of age $[17,18]$. This question was correctly answered by $54 \%$. A serum IgG level of $350 \mathrm{mg} / \mathrm{dL}$ is acceptable up to one year of age; followed by a gradual increase until 6 years of age $(\geq 600 \mathrm{mg} / \mathrm{dL})$ [15]; this item was incorrectly selected by $35 \%$. These results suggest that attentiveness to normal laboratory values as function of age is limited.

Table 5 and Figure 1 show the overall performance scores (not including the management questions) and classifying the sum of correct answers to three levels of competency: $\geq 80 \%, 60$ to $79 \%$ and $<60 \%$. The majority (76\%) of pediatricians correctly answered 60 to $79 \%$ of the questions, and only $4 \%$ correctly answered $\geq 80 \%$ of the questions. Significant differences were noted between the two main categories ( $p$-value $<0.001$, Wilcoxon signed rank test), with a better knowledge score

\section{Table 4 Which of the following results suggest PID?}

\begin{tabular}{|c|c|}
\hline & Percent answered "yes" \\
\hline $\begin{array}{l}\text { Absent delayed hypersensitivity skin reaction } \\
\text { to Candida in a } 6 \text {-month-old infant * }\end{array}$ & 74 \\
\hline Giant granules in neutrophils & 64 \\
\hline $\begin{array}{l}\text { Absolute lymphocyte count }<2,500 / \mu \mathrm{L} \\
\text { in a 4-month-old infant }\end{array}$ & 54 \\
\hline Small size platelets & 44 \\
\hline $\begin{array}{l}\text { Serum lgG level } 350 \mathrm{mg} / \mathrm{dL} \text { in a } \\
\text { 7-month-old infant * }\end{array}$ & 35 \\
\hline Neonatal thrombocytopenia & 31 \\
\hline
\end{tabular}

* Not a finding that suggests PID.

(The order of the items is presented according to the percentage picked by respondents, not how it appeared in the questionnaire). 
Table 5 The performance scores

\begin{tabular}{|c|c|c|c|}
\hline $\begin{array}{l}\text { Performance } \\
\text { score }^{*}\end{array}$ & $\frac{\text { Knowledge }^{\dagger}}{(\text { Tables 1, 2) }}$ & $\frac{\text { Investigation }^{\dagger}}{(\text { Tables } 3,4)}$ & $\frac{\text { Overall }^{\dagger}}{\text { Tables } 1,2,3,4)^{\text {Tablo }}}$ \\
\hline$<60$ & $15 \%$ & $54 \%$ & $20 \%$ \\
\hline 60 to $79 \%$ & $63 \%$ & $44 \%$ & $76 \%$ \\
\hline$\geq 80 \%$ & $22 \%$ & $2 \%$ & $4 \%$ \\
\hline
\end{tabular}

(95\% CI: 69.7, 72.7) than investigation/interpretation score (95\% CI: $52.9,55.9)$.

The overall performance scores did not significantly differ with age (Poisson regression, likelihood ratio test $p=0.736)$, gender $(p=0.382)$, certification $(p=0.435)$, rank $(p=0.829)$ and experience $(p=0.706)$. Similarly, the knowledge and investigation/interpretation scores (when assessed separately) did not differ with age, gender, certification, rank and experience (all $p>0.20$ ).

Intravenous immunoglobulin dosing and administration intervals were also tested. Sixty-five percent choose a dose of 400 to $600 \mathrm{mg} / \mathrm{kg}$ and $80 \%$ choose 3 to 4 week dosing intervals [1]. Eight percent did not consider $\mathrm{mg} / \mathrm{kg}$ as a basis for dosing. For prophylactic antibiotics, 44\% recommended co-trimoxazole, $21 \%$ recommended penicillins and $23 \%$ recommend none.

Overall, $47 \%$ had at least a patient with PID, $41 \%$ had referred a patient for PID assessment, and $12 \%$ had neither evaluated nor referred a patient with PID. Only 9\% of the pediatricians were completely comfortable with PID patients, 59\% were somewhat comfortable, and 32\% were not comfortable.

\section{Discussion}

The most important finding of this study was the fact that most pediatricians (despite their diverse education, ranks and years of experience) recognized the common signs and symptoms of PID. There were significant

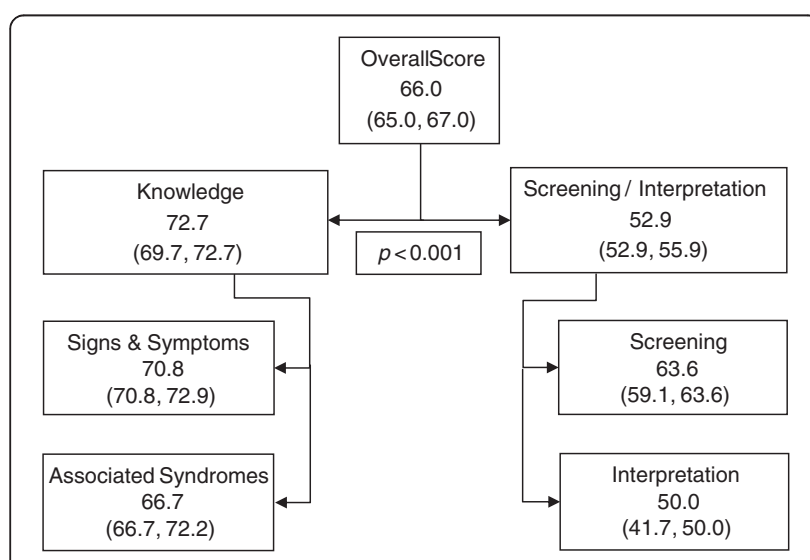

Figure 1 Median percent scores (95\% confidence intervals for median percent scores) per categories. problems, however, in requesting the appropriate tests, identifying the age-appropriate reference values and interpreting the results. Although the theoretical knowledge is reasonable, these data show limitations in practicing for children suspected to have PID. It worth noting that despite the study aimed primarily to assess knowledge in practicing pediatricians, $26 \%$ of the participants were house officers or pediatric residents. Interpreting laboratory results should discern normal values for age, as the first few years reveal enormous immune maturation [2].

PID knowledge and practice have been explored in a limited number of studies. In a study from Kuwait, $26 \%$ of the pediatricians correctly answered $\geq 67 \%$ of the questions. The mean overall score was $60 \%$ (95\% confidence interval $=58 \%$ to $61 \%$ ), the clinical presentation score was $63 \%$, the syndromes associated with immunodeficiency score was $58 \%$, and the laboratory investigation score was $51 \%$. It was uncertain, however, whether these results are applicable to other countries and repeated studies are recommended [13]. Another study from Turkey investigated only the awareness of pediatricians to important PID indicators. Family history was identified by $91 \%$, persistent thrush by $90 \%$, consanguineous marriages by $87 \%$, telangiectasia by $82 \%$, failure to thrive by $79 \%$, neonatal tetany by $78 \%$, absence of tonsils by $75 \%$, oculocutaneous albinism by $74 \%$, hospitalization for recurrent infection by $71 \%$, resistant sinusitis by $71 \%$, infant deaths by $70 \%$, giardiasis by $62 \%$, liver abscess by $61 \%$, recurrent oral aphthous by $59 \%$ and poliomyelitis following oral polio vaccination by $51 \%$ [19].

Early diagnosis of PID is essential to avoid serious sequelae. Comprehensive immune work-up that includes genetic analysis is not readily available in many parts of the world. Nevertheless, this short coming was usually not the reason for the delayed diagnosis. It has been shown that hindrance in PID diagnosis hinges mainly on proper consideration of the clinical and laboratory findings [20].

The cornerstones for PID diagnosis are medical history (focused on recognizing PID symptoms), physical examination (focused on indicative PID signs) and laboratory investigation (focused on pathognomonic recognition of the anomalies). These foundations need to be implemented as a practical diagnostic strategy.

Proper patient management should promptly follow the diagnosis. Immunoglobulin and antimicrobial therapies are usually available. Allogeneic hematopoietic stem cell transplantation, on the other hand, requires referral to a tertiary center. Other modalities include gene (e.g., severe combined immune deficiency and chronic granulomatous disease), enzyme (e.g., adenosine deaminase deficiency) and immune modulation (e.g., immune dysregulation) therapies [1]. 
Establishing a national registry is a critical need and would serve numerous purposes. It would provide epidemiological data, and address ethnical and geographical variations [10]. Rezaei et al. documented improved recognition of PID disorders following the creation of PID registries [20]. Simplifying the educational materials and provision of interactive learning appear to be more effective than conventional Continuous Medical Education courses. Training strategies should include understanding the development of the immune system, comprehending the complexity of the investigations and interpreting the results appropriately.

\section{Conclusions}

The clinical gaps reported here likely stem from inadequate engagements of pediatricians in the work-up of children with PID. The usual practice is to refer these patients to immunologists without effective investigation. Moreover, the communication between immunologists and pediatricians typically ceases at patient referral. This practice is further enforced by fears involved in caring for these vulnerable patients. Since these disorders are relatively rare, opportunities to be familiar with them are relatively infrequent.

The clinical practice needs to allow pediatricians to take initiatives and provide care for PID patients, especially with limited number of immunologists worldwide. Immunologists should encourage pediatricians' involvement in the patient care and make themselves available for consultations. The exchanges between immunologists and pediatricians should be informative and educational. Pediatricians, on the other hand, may need to concentrate more on pattern recognition, work-up and laboratory interpretation rather than molecular diagnosis.

\section{Competing interests}

The authors declare that they have no competing interests.

\begin{abstract}
Authors' contributions
SAH and AKS have made substantial contributions to conception and design, acquisition of data, and analysis and interpretation of data. They also have been involved in drafting the manuscript and revising it critically for important intellectual content. EAR, SAR, KAZ, RAZ and HAS have made substantial contributions to acquisition of data, and have given their final approval of the version to be published. TZ have made substantial contributions to analysis and interpretation of data, and have given final approval of the version to be published. All authors read and approved the final manuscript.
\end{abstract}

\section{Authors' information}

$\mathrm{SAH}$ is Clinical Immunologist in the Faculty of Medicine and Health Sciences (FMHS) - UAE University. AKS is Chairman of the Department of Pediatrics (FMHS - UAE University). TZ is biostatistician (UAE University). EAR, SAR, KAZ, RAZ and HAS are pediatricians practicing in the UAE.

\section{Acknowledgments}

We would like to thank the Faculty of Medicine and Health Sciences at UAE University for the financial support. Also, we thank sincerely the pediatricians at different hospitals who took the responsibility to follow up on the completion of the survey: Dr Anwar Sallam, Al-Mafraq Hospital, Dr Amin Abu
Bakr, Al-Rahba Hospital, Drs Aisha Al-Shattaf and Sabeeha Al-Tunaiji, Tawam Hospital, Dr Khalid Abu Ahmad, Madinat Zayed Hospital, Dr Wahib Marzouq, Ruwais Hospital, Dr Saif Al-Kaabi, Zayed Military Hospital, Dr Alla Shaheen, Al-Baraha hospital, Dr Mohamed Anwar Tufail, Al-Qasimi Hospital, Dr Raef El-Gamal, Sheikh Khalifa Hospital, Dr Fawzeya Abu Al-Assaad, Umm Al-Quwain Hospital, Dr Abdelmalik A Razik, Fujairah Hospital, Dr Saad Alaani, Khorfakkan hospital, and all the pediatricians who gave time to participate in this study. Last, but not least, Dr Walid Al-Herz for sharing with us the main structure of the survey used in his study [13].

\section{Author details}

${ }^{1}$ Department of Pediatrics, Faculty of Medicine and Health Sciences, UAE University, P.O. Box 17666, Al-Ain, United Arab Emirates. ${ }^{2}$ Department of Pediatrics, Saqr Hospital, Ras Al-Khimah, United Arab Emirates. ${ }^{3}$ Department of Pediatrics, Sheikh Khalifa Medical City, Abu Dhabi, United Arab Emirates. ${ }^{4}$ Department of Pediatrics, Kalba Hospital, Sharjah, United Arab Emirates. ${ }^{5}$ Department of Pediatrics, Al-Wasl Hospital, Dubai, United Arab Emirates. ${ }^{6}$ Department of Pediatrics, Dubai Hospital, Dubai, United Arab Emirates. ${ }^{7}$ Department of Statistics, Faculty of Business and Economics, UAE University, Al-Ain, United Arab Emirates.

Received: 9 December 2011 Accepted: 20 July 2012

Published: 31 July 2012

\section{References}

1. Ochs HD, Stiehm R, Winkelstein J: Antibody deficiencies. In Immunologic disorders in infants \& children. 5th edition. Edited by Ochs HD, Stiehm R, Winkelstein J. Philadelphia: Elsevier Saunders; 2004:356-426.

2. Leung DYM, Sampson HA, Geha R, Szefler SJ: Pediatric Allergy Principles and Practice. 2nd edition. Philadelphia: Elsevier Saunders; 2010.

3. Nicolay U, Kiessling P, Berger M, Gupta S, Yel L, Roifman CM, Gardulf A, Eichmann F, Haag S, Massion C, Ochs HD: Health-related quality of life and treatment satisfaction in North American patients with primary immunodeficiency diseases receiving subcutaneous IgG self-infusion at home. J Clin Immunol 2006, 26(1):65-72.

4. Aghamohammadi A, Montazeri A, Abolhassani H, Saroukhani S, Pourjabbar S, Tavassoli M, Darabi B, Imanzadeh A, Parvaneh N, Rezaei N: Health-related quality of life in primary antibody deficiency. Iran J Allergy Asthma Immunol 2011, 10(1):47-51.

5. Al-Herz W, Bousfiha A, Casanova JL, Chapel H, Conley ME, CunninghamRundles C, Etzioni A, Fischer A, Franco JL, Geha RS, Hammarström L, Nonoyama S, Notarangelo LD, Ochs HD, Puck JM, Roifman CM, Seger R, Tang MLK: Primary Immunodeficiency Diseases: an update on the Classification from the International Union of Immunological Societies Expert Committee for Primary Immunodeficiency. Front Immunol 2011, 2:1-26.

6. Jeffrey Modell foundation website. [http://www.jmfworld.com] (August 30, 2011.

7. Boyle JM, Buckley RH: Population prevalence of diagnosed primary immunodeficiency diseases in the United States. J Clin Immunol 2007, 27(5):497-502.

8. Wood P, Herriot R, Jones A, Chapel H, Burton J, Stanworth S, Peckham D, Hyde C, Hughan C: (UK Primary Immunodeficiency Network). Primary antibody deficiencies: recognition, clinical diagnosis and referral of patients. Clin Med 2009, 9(6):595-599.

9. Subbarayan A, Colarusso G, Hughes SM, Gennery AR, Slatter M, Cant AJ, Arkwright PD: Clinical features that identify children with primary immunodeficiency diseases. Pediatrics 2011, 127(5):810-816.

10. Al-Herz W: Primary immunodeficiency disorders in Kuwait: first report from Kuwait National Primary Immunodeficiency Registry (2004-2006). J Clin Immunol 2008, 28(2):186-193.

11. Rezaei N, Pourpak Z, Aghamohammadi A, Farhoudi A, Movahedi M, Gharagozlou M, Mirsaeid Ghazi B, Atarod L, Abolmaali K, Mahmoudi M, Mansouri D, Arshi S, Tarash NJ, Sherkat R, Amin R, Kashef S, Hosseini RF, Mohammadzadeh I, Shabestari MS, Nabavi M, Moin M: Consanguinity in primary immunodeficiency disorders; the report from Iranian Primary Immunodeficiency Registry. Am J Reprod Immunol 2006, 56(2):145-151.

12. Reda SM, Afifi HM, Amine MM: Primary immunodeficiency diseases in Egyptian children: a single-center study. J Clin Immunol 2009, 29(3):343-351 
13. Al-Herz W, Zainal ME, Salama M, Al-Ateeqi W, Husain K, Abdul-Rasoul M, AlMutairi B, Badawi M, Aker N, Kumar S, Al-Khayat H: Primary immunodeficiency disorders: survey of pediatricians in Kuwait. J Clin Immunol 2008, 28(4):379-383.

14. Kersseboom R, Brooks A, Weemaes C: Educational paper: syndromic forms of primary immunodeficiency. Eur J Pediatr 2011, 170(3):295-308

15. Bonilla F: Antibody Deficiency. In Pediatric Allergy Principle and Practice. 2nd edition. Edited by Leung DYM, Sampson HA, Geha R, Szefler SJ.

Philadelphia: Elsevier Saunders; 2010:88-97.

16. Kniker WT, Lesourd BM, McBryde JL, Corriel RN: Cell-mediated immunity assessed by Multitest CMI skin testing in infants and preschool children. Am J Dis Child 1985, 139(8):840-845.

17. Appendix 1: Clinical Immunology Laboratory value. In Pediatric Allergy Principle and Practice. 2nd edition. Edited by Leung DYM, Sampson HA, Geha R, Szefler SJ. Philadelphia: Elsevier Saunders; 2010:664-665.

18. Adeli MM, Buckley RH: Why newborn screening for severe combined immunodeficiency is essential: a case report. Pediatrics 2010, 126(2):e465-e469.

19. Yüksek M, Ikincioğullari A, Doğu F, Elhan A, Yüksek N, Reisli I, Babacan E: Primary immune deficiency disease awareness among a group of Turkish physicians. Turk J Pediatr 2010, 52(4):372-377.

20. Rezaei N, Aghamohammadi A, Moin M, Pourpak Z, Movahedi M, Gharagozlou M, Atarod L, Ghazi BM, Isaeian A, Mahmoudi M, Abolmaali K, Mansouri D, Arshi S, Tarash NJ, Sherkat R, Akbari H, Amin R, Alborzi A, Kashef S, Farid R, Mohammadzadeh I, Shabestari MS, Nabavi M, Farhoudi A: Frequency and clinical manifestations of patients with primary immunodeficiency disorders in Iran: update from the Iranian Primary Immunodeficiency Registry. J Clin Immunol 2006, 26(6):519-532.

doi:10.1186/1756-0500-5-393

Cite this article as: Al-Hammadi et al: Attentiveness of pediatricians to primary immunodeficiency disorders. BMC Research Notes 2012 5:393.

\section{Submit your next manuscript to BioMed Central and take full advantage of:}

- Convenient online submission

- Thorough peer review

- No space constraints or color figure charges

- Immediate publication on acceptance

- Inclusion in PubMed, CAS, Scopus and Google Scholar

- Research which is freely available for redistribution 